\title{
Adsorption Isotherms for Xenon and Krypton using INL HZ-PAN and AgZ-PAN Sorbents
}

Troy G. Garn, Mitchell Greenhalgh, Veronica Rutledge and Jack D. Law

August 2014

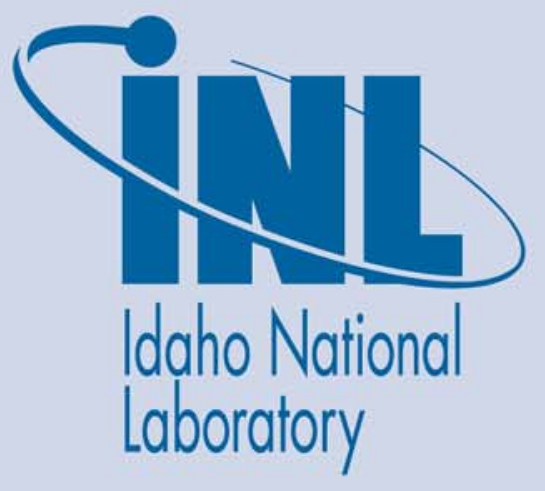

The INL is a U.S. Department of Energy National Laboratory operated by Battelle Energy Alliance 
INL/EXT-14-32920

\title{
Adsorption Isotherms for Xenon and Krypton using INL HZ-PAN and AgZ-PAN Sorbents
}

\author{
Troy G. Garn, Mitchell Greenhalgh, Veronica Rutledge and Jack D. Law
}

AUGUST 2014

\author{
Idaho National Laboratory \\ Idaho Falls, Idaho 83415
}

http://www.inl.gov

Prepared for the

U.S. Department of Energy

Office of Nuclear Energy

Under DOE Idaho Operations Office

Contract DE-AC07-05ID14517 


\section{Adsorption Isotherms for Xenon and Krypton using INL HZ-PAN and AgZ-PAN Sorbents \\ Fuel Cycle Technology}

Prepared for U.S. Department of Energy Material Recovery and Waste Form Development Troy G. Garn, Mitchell Greenhalgh, Veronica Rutledge and Jack D. Law National Laboratory August 29, 2014 FCRD-SWF-2014-000270 INL/EXT-14-32920 



DISCLAIMER
This information was prepared as an account of work sponsored by an agency of the U.S. Government. Neither
the U.S. Government nor any agency thereof, nor any of their employees, makes any warranty, expressed or
implied, or assumes any legal liability or responsibility for the accuracy, completeness, or usefulness, of any
information, apparatus, product, or process disclosed, or represents that its use would not infringe privately
owned rights. References herein to any specific commercial product, process, or service by trade name, trade
mark, manufacturer, or otherwise, does not necessarily constitute or imply its endorsement, recommendation, or
favoring by the U.S. Government or any agency thereof. The views and opinions of authors expressed herein do
not necessarily state or reflect those of the U.S. Government or any agency thereof.





\section{SUMMARY}

The generation of adsorption isotherms compliments the scale-up of off-gas processes used to control the emission of encapsulated radioactive volatile fission and activation products released during Used Nuclear Fuel (UNF) reprocessing activities.

A series of experiments were conducted to obtain capacity results for varying $\mathrm{Kr}$ and Xe gas concentrations using HZ-PAN and AgZ-PAN engineered form sorbents. Gas compositions ranged from 150-40,000 ppmv for $\mathrm{Kr}$ and 250-5020 ppmv for Xe in a helium balance. The experiments were all performed at $220 \mathrm{~K}$ at a flowrate of $50 \mathrm{sccm}$.

Acquired capacities were then respectively fit to the Langmuir equation using the Langmuir linear regression method to obtain the equilibrium parameters $\mathrm{Q}_{\max }$ and $\mathrm{K}_{\text {eq. }}$ Generated experimental adsorption isotherms were then plotted with the Langmuir predicted isotherms to illustrate agreement between the two.

The Langmuir parameters were provided for input into the Off-gas SeParation and RecoverY (OSPREY) model to predict breakthrough of single component adsorption of $\mathrm{Kr}$ and Xe on HZ-PAN and AgZ-PAN sorbents at the experimental conditions tested. $\mathrm{Kr}$ and $\mathrm{Xe}$ capacities resulting from model breakthrough predictions were then compared to experimental capacities for model validation.

There was good agreement with the experimental and predicted capacity values for both $\mathrm{Kr}$ and Xe on HZ-PAN and AgZ-PAN sorbents. Predicted Kr capacities were $6.9 \mathrm{mmol} / \mathrm{kg}$ for both sorbents and the experimental $\mathrm{Kr}$ capacities were 6.0 and $5.7 \mathrm{mmol} / \mathrm{kg}$ for HZ-PAN and AgZ-PAN respectively. For Xe adsorption, predicted capacities were 558 and $562 \mathrm{mmol} / / \mathrm{kg}$ for HZ-PAN and AgZ-PAN respectively while experimental Xe capacities of 507 and $506 \mathrm{mmol} / \mathrm{kg}$ were achieved. Overall, the model predicted slightly elevated capacities for both $\mathrm{Kr}$ and Xe for both sorbents which can be partially attributed to the estimation of the parameters and the uncertainty associated with the experimental measurements. 


\section{CONTENTS}

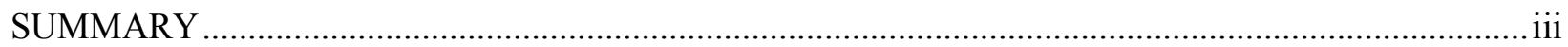

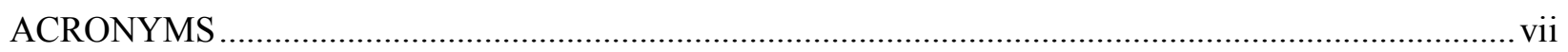

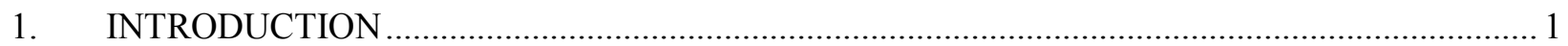

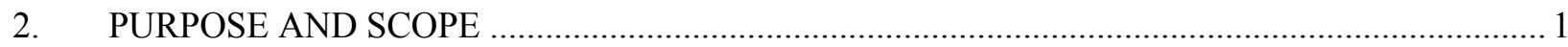

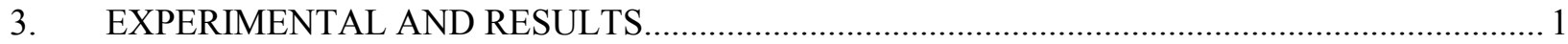

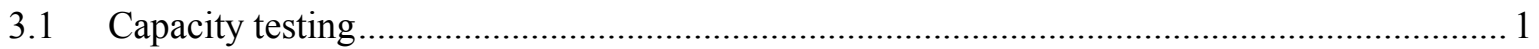

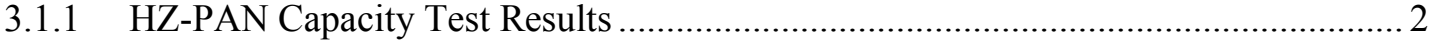

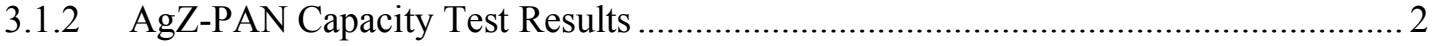

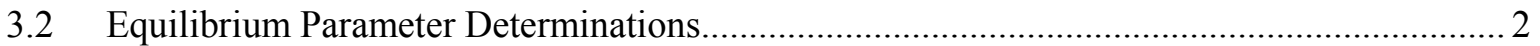

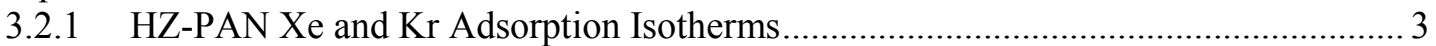

3.2.2 AgZ-PAN Xe and $\mathrm{Kr}$ Adsorption isotherms ......................................................... 4

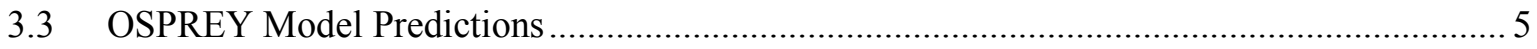

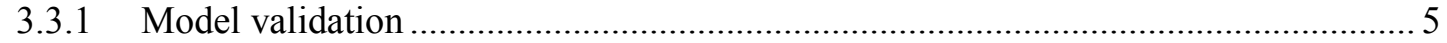

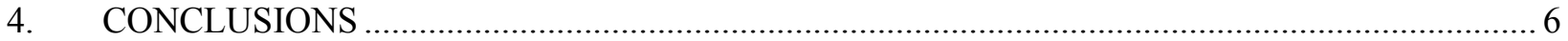

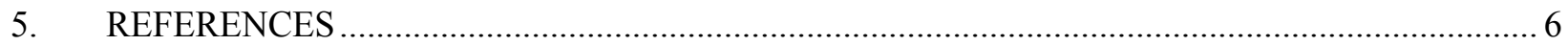

\section{FIGURES}

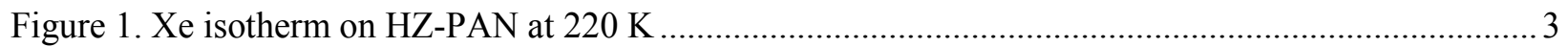

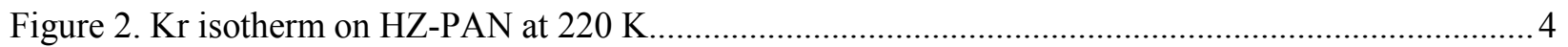

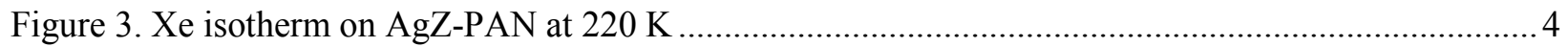

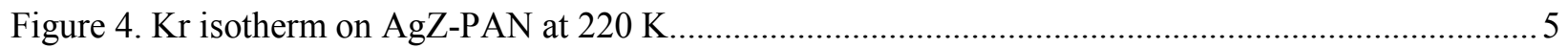

\section{TABLES}

Table 1. Kr and Xe capacities for varying gas concentrations using HZ-PAN ...................................... 2

Table 2. $\mathrm{Kr}$ and $\mathrm{Xe}$ capacities for varying gas concentrations using AgZ-PAN...................................... 2

Table 3. Langmuir Equilibrium Parameters........................................................................................ 3

Table 4. OSPREY predicted capacities compared to experimentally determined capacities..................... 6 


\section{ACRONYMS}

AgZ-PAN Silver converted form Mordenite- Polyacrylonitrile

HZ-PAN Hydrogen form Mordenite-Polyacrylonitrile

OSPREY Off-gas SeParations REcoverY Model

UNF Used Nuclear Fuel 


\section{ADSORPTION ISOTHERMS FOR XENON AND KRYPTON USING HZ-PAN AND AgZ-PAN SORBENTS}

\section{INTRODUCTION}

The release of volatile radionuclides generated during Used Nuclear Fuel (UNF) reprocessing in the US will most certainly need to be controlled to meet US regulatory emission limits.

A US DOE sponsored Off-Gas Sigma Team has been tasked with a multi-lab collaborative research and development effort to investigate and evaluate emissions and immobilization control technologies for the volatile radioactive species generated from commercial UNF reprocessing.

The physical adsorption process is currently being evaluated for the capture of krypton and xenon at INL and has resulted in a novel composite sorbent development procedure using commercially available mordenite powder as the active material bound with polyacrylonitrile (PAN).

Utilizing this sorbent development procedure, INL sigma team members have developed two composite sorbents that have been evaluated using krypton and xenon capacity measurements. Single component adsorption isotherms have been generated to predict Langmuir equilibrium constants $\left(\mathrm{K}_{\mathrm{eq}}\right)$ and maximum capacities $\left(\mathrm{Q}_{\max }\right)$.

\section{PURPOSE AND SCOPE}

Results from previous isotherm studies indicated that capacity tests with higher $\mathrm{Kr} / \mathrm{Xe}$ gas concentration test gases would provide better agreement with predicted $\mathrm{Q}_{\max }$ values. Experimental capacities using previous test gas concentrations ( $2500 \mathrm{ppmv} \mathrm{Kr}$ and $1040 \mathrm{ppmv} \mathrm{Xe}$ ) were generally quite lower than the predicted Langmuir $\mathrm{Q}_{\max }$ values. The intent of this work was to obtain capacity measurements that were closer to the predicted $\mathrm{Q}_{\max }$ values thus, producing a more accurate adsorption isotherm. Test gases of 40,000 ppmv $\mathrm{Kr}$ and 5020 ppmv Xe were diluted with He to the desired concentration and adsorption capacities were obtained for both the HZ-PAN and AgZ-PAN sorbents. These capacities were then used to determine the $\mathrm{K}_{\mathrm{eq}}$ and $\mathrm{Q}_{\max }$ parameters by the Langmuir linear regression method. Langmuir predicted isotherms were then plotted with the generated experimental adsorption isotherms to illustrate better agreement between the two.

\section{EXPERIMENTAL AND RESULTS}

Capacity tests using $\mathrm{Kr} / \mathrm{He}$ and $\mathrm{Xe} / \mathrm{He}$ test gases were completed using the experimental setup incorporating the custom designed cryostat. The results from the capacity tests were used to generate $\mathrm{Kr}$ and Xe adsorption isotherms for both HZ-PAN and AgZ-PAN sorbents. The experimentally determined equilibrium constant and maximum capacity for each isotherm was input into the OSPREY model using selected test conditions for development of breakthrough curves where predicted capacities were calculated and compared to the experimentally obtained capacity measurements for model validation.

\subsection{Capacity testing}

Capacity tests for HZ-PAN and AgZ-PAN sorbents were completed at $220 \mathrm{~K}$ at gas flowrates of $50 \mathrm{sccm}$, while varying $\mathrm{Kr} / \mathrm{He}$ and $\mathrm{Xe} / \mathrm{He}$ feed gas concentration. $\mathrm{Kr}$ test gas concentrations ranged from 150 40000 ppmv and Xe test gas concentrations ranged from 240-5020 ppmv.

At the conclusion of each capacity test, a sorbent bakeout was performed by flowing UHP He at $50 \mathrm{sccm}$ through the column heated to $385 \mathrm{~K}$ to desorb the $\mathrm{Kr}$ or Xe from the column while monitoring the column effluent gas flow with a gas chromatograph (GC) to ensure the $\mathrm{Kr}$ or Xe had been removed prior to initiating the next test. Adsorption isotherms were generated for both $\mathrm{Kr} / \mathrm{He}$ and $\mathrm{Xe} / \mathrm{He}$ gas compositions for both engineered form sorbents from the capacity data generated. 


\subsubsection{HZ-PAN Capacity Test Results}

Table 1 includes the associated capacities obtained for varying $\mathrm{Kr}$ and $\mathrm{Xe}$ concentrations at $220 \mathrm{~K}$ for HZ-PAN.

Table 1. Kr and Xe capacities for varying gas concentrations using HZ-PAN

\begin{tabular}{|c|c|c|c|}
\hline Kr Conc. (ppmv) & Capacity (mmol/kg) & Xe Conc. (ppmv) & Capacity $(\mathrm{mmol} / \mathrm{kg})$ \\
\hline 861 & 44 & 250 & 185 \\
\hline 1707 & 79 & 502 & 345 \\
\hline 2634 & 93 & 755 & 462 \\
\hline 5000 & 189 & 1040 & 507 \\
\hline 10000 & 377 & 2510 & 808 \\
\hline 20000 & 514 & 5020 & 1070 \\
\hline 40000 & 886 & & \\
\hline
\end{tabular}

\subsubsection{AgZ-PAN Capacity Test Results}

Table 2 includes the associated capacities obtained for varying $\mathrm{Kr}$ and $\mathrm{Xe}$ concentrations at $220 \mathrm{~K}$ for AgZ-PAN.

Table 2. Kr and Xe capacities for varying gas concentrations using AgZ-PAN

\begin{tabular}{ccccc} 
Kr Conc. (ppmv) & Capacity $(\mathrm{mmol} / \mathrm{kg})$ & & Xe Conc. $(\mathrm{ppmv})$ & Capacity $(\mathrm{mmol} / \mathrm{kg})$ \\
\hline \hline 749 & 31 & & 104 & 118 \\
1353 & 57 & 300 & 252 \\
1934 & 81 & 520 & 343 \\
2544 & 106 & 1000 & 506 \\
10000 & 257 & 2510 & 724 \\
20000 & 417 & 5020 & 898 \\
40000 & 670 & &
\end{tabular}

\subsection{Equilibrium Parameter Determinations}

The Langmuir equilibrium parameters were determined by performing a linear regression of the capacity data by creating a plot of the feed gas concentration $(C)$ vs. the ratio of concentration over capacity $(\mathrm{C} / \mathrm{Q})$, Where the slope of the line is equal to $1 / \mathrm{Q}_{\max }$ and the intercept is equal to $1 /\left(\mathrm{K}_{\mathrm{eq}}{ }^{*} \mathrm{Q}_{\max }\right)$. These parameters were inserted into the Langmuir equation to generate a plot of the predicted isotherms and the experimental capacities were added to the plots for reference. The obtained equilibrium parameters are shown in Table 3. 
Table 3. Langmuir Equilibrium Parameters

\begin{tabular}{ccc} 
Adsorption Conditions & $\mathrm{K}_{\mathrm{eq}}\left(\mathrm{m}^{3} / \mathrm{mol}\right)$ & $\mathrm{Q}_{\max }(\mathrm{mol} / \mathrm{kg})$ \\
\hline \hline HZ-PAN Xe & 14.7 & 1.40 \\
HZ-PAN Kr & 0.65 & 1.64 \\
AgZ-PAN Xe & 23.7 & 1.06 \\
AgZ-PAN Kr & 0.96 & 1.03
\end{tabular}

\subsubsection{HZ-PAN Xe and $\mathrm{Kr}$ Adsorption Isotherms}

The adsorption isotherms generated for both Xe and $\mathrm{Kr}$ on HZ-PAN can be found in Figures 1 and 2 respectively. It can be seen from the graphs that the Langmuir predicted isotherm agrees well with the experimentally obtained values.

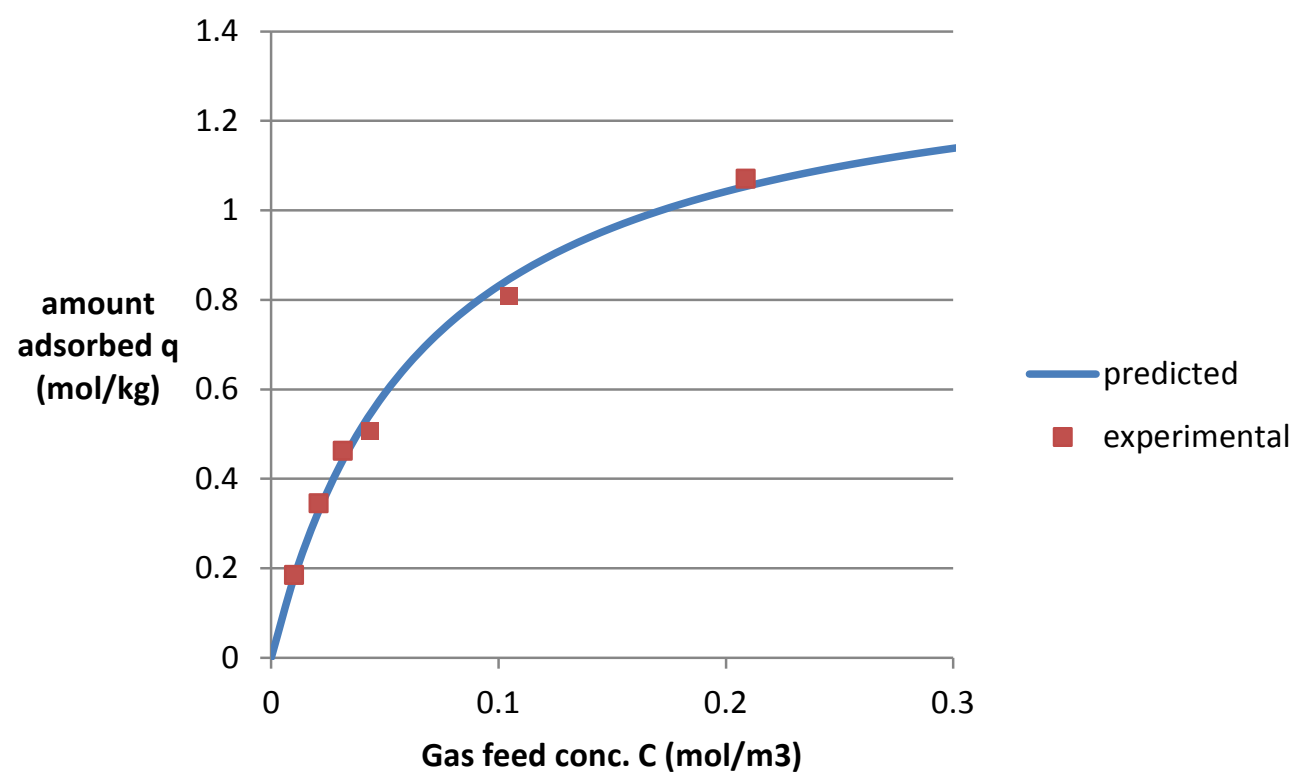

Figure 1. Xe isotherm on HZ-PAN at $220 \mathrm{~K}$ 


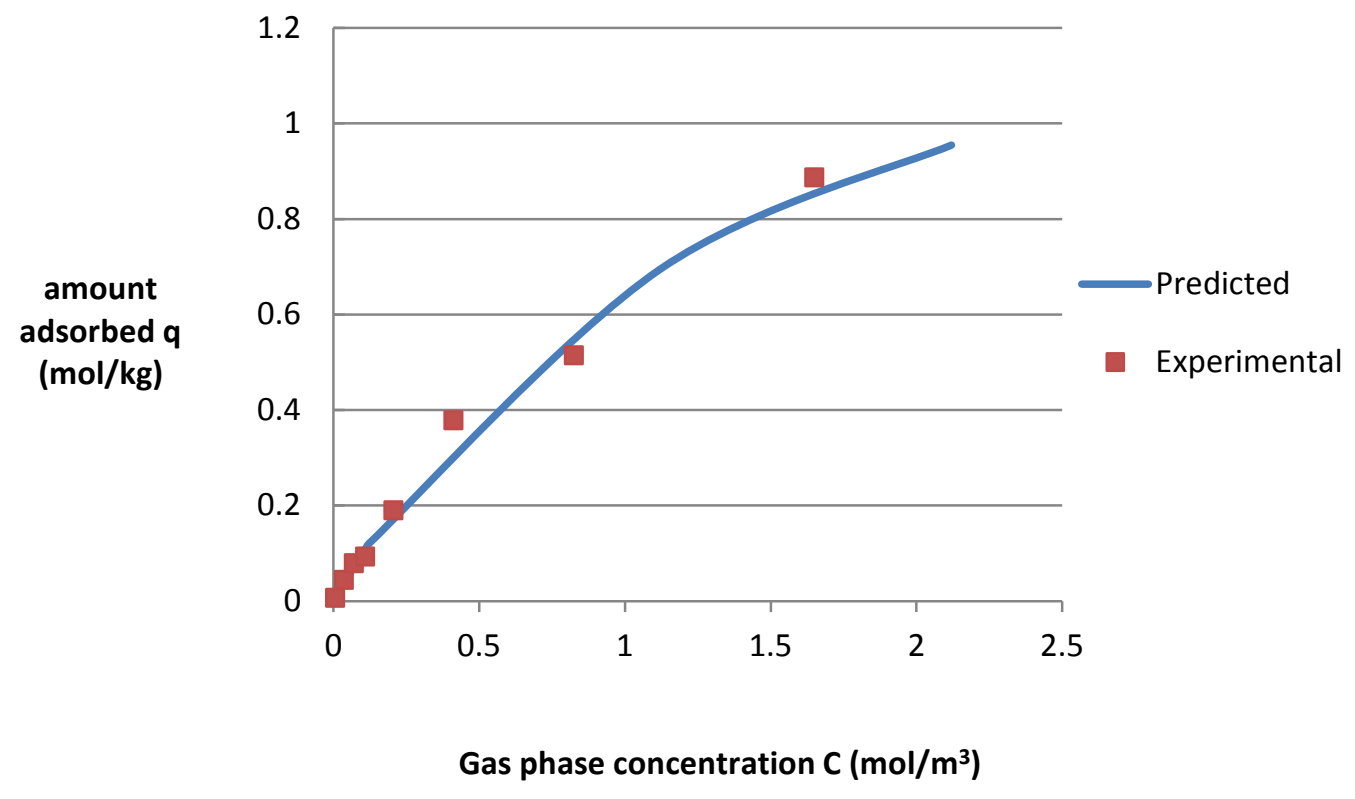

Figure 2. $\mathrm{Kr}$ isotherm on HZ-PAN at $220 \mathrm{~K}$

\subsubsection{AgZ-PAN Xe and Kr Adsorption isotherms}

The adsorption isotherms generated for both $\mathrm{Xe}$ and $\mathrm{Kr}$ on AgZ-PAN can found in Figures 3 and 4 respectively. It can be seen from the graphs that the Langmuir predicted isotherm agrees well with the experimentally obtained values for Xe. The Langmuir prediction for $\mathrm{Kr}$ adsorption on AgZ-PAN does not agree with the empirical data as well as the other predictions agree with their respective empirical data. This is most likely due to the lower capacity for $\mathrm{Kr}$ on the AgZ-PAN.

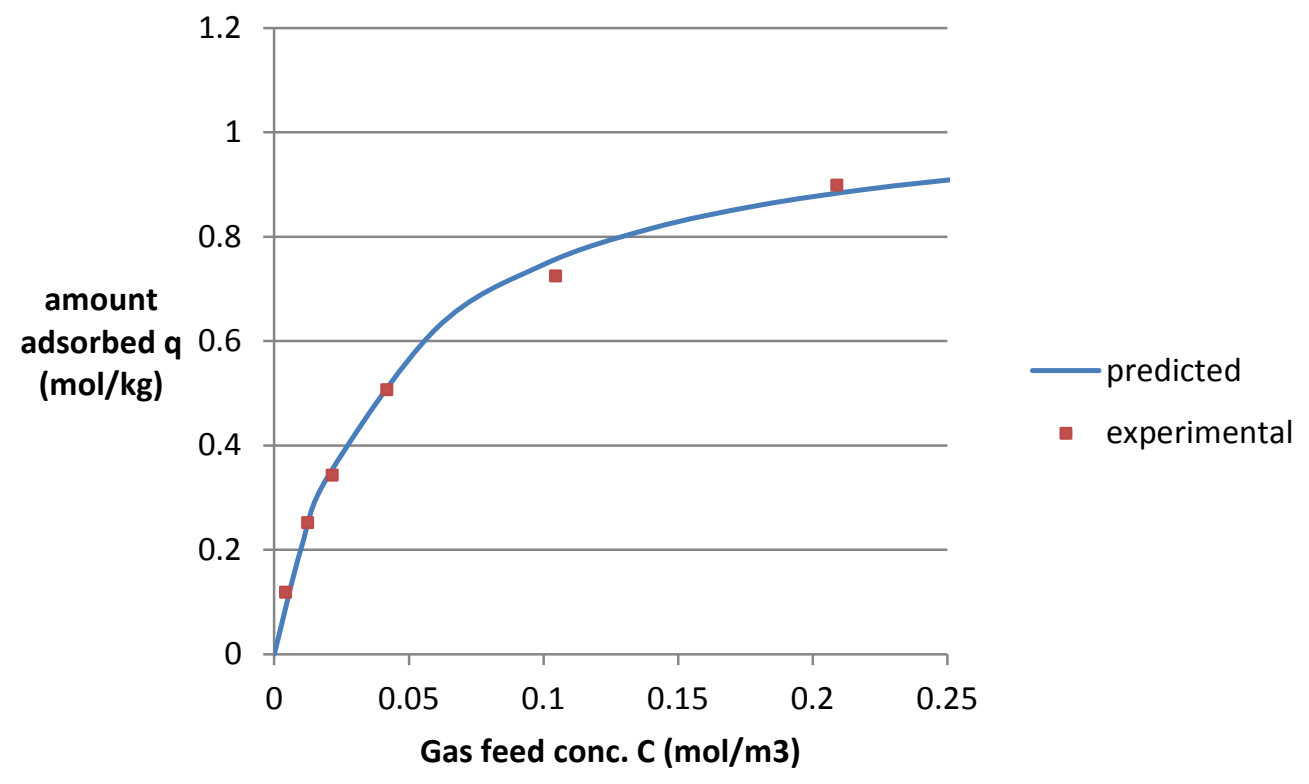

Figure 3. Xe isotherm on AgZ-PAN at $220 \mathrm{~K}$ 


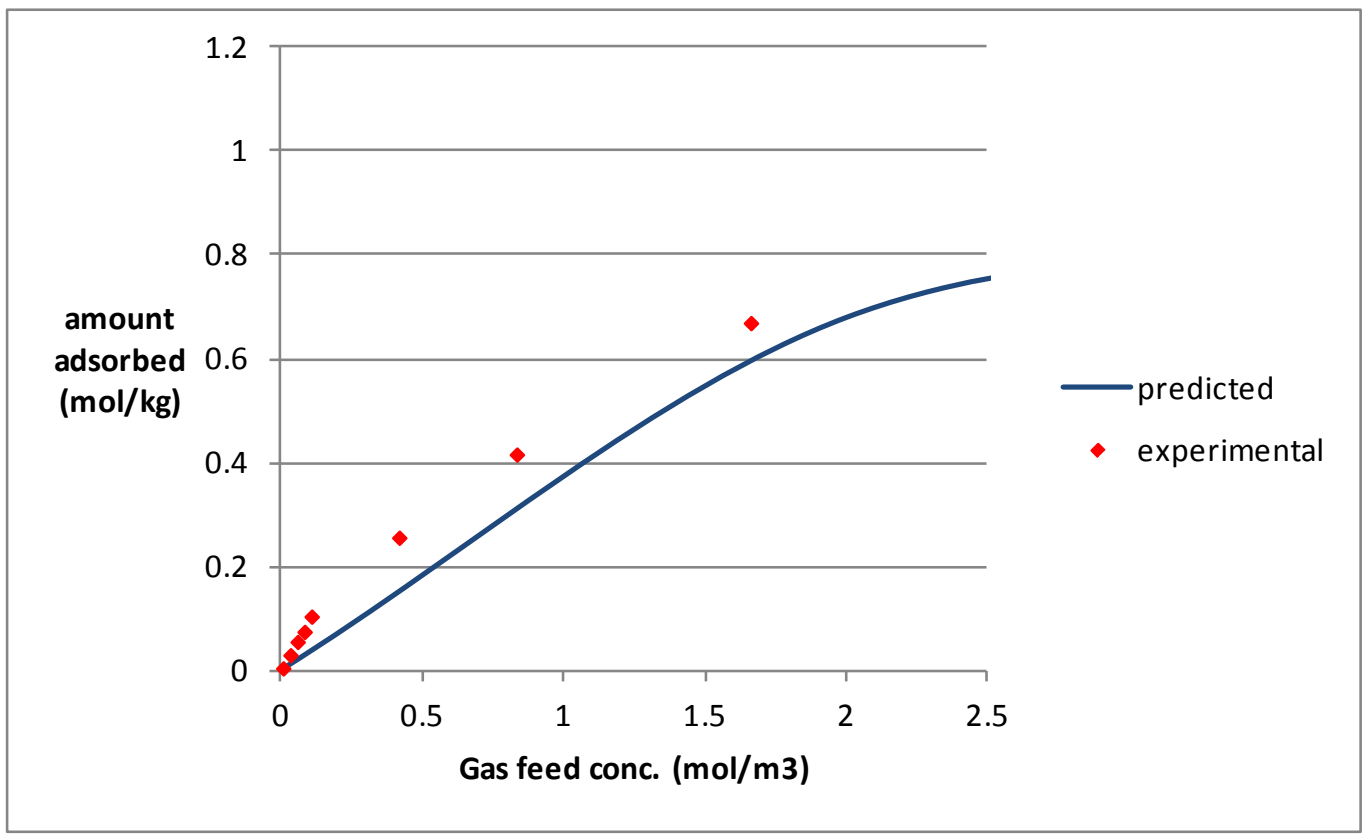

Figure 4. $\mathrm{Kr}$ isotherm on AgZ-PAN at $220 \mathrm{~K}$

\subsection{OSPREY Model Predictions}

The OSPREY model has been developed to solve the fundamental transport equations for adsorption in a packed bed in order to obtain a predictive unit operations model for the separation of off-gas constituents. It is a dynamic fully coupled off-gas adsorption model that has been developed in the MOOSE framework to solve off-gas separation systems of equations simultaneously in a fully implicit manner using finite elements methods. OSPREY models the adsorption of off- gas constituents for dispersed plug flow in a packed bed under non-isothermal and non-isobaric conditions. Inputs to the model include gas composition, sorbent and column properties, equilibrium and kinetic data, and inlet conditions. The simulation outputs component concentrations along the column length as a function of time from which breakthrough data can be obtained. The breakthrough data can be used to determine bed capacity ${ }^{1}$, which in turn can be used to size columns. In addition to concentration data, the model predicts temperature along the column length as a function of time and pressure drop along the column length.

\subsubsection{Model validation}

To validate and evaluate OSPREY for further increasing its fidelity, the isotherm data experimentally generated for krypton and xenon adsorption on HZ PAN and AgZ PAN, along with experimental conditions, have been input into the model to generate predicted breakthrough curves for four cases. These breakthrough curves were then used to determine capacities for direct comparison with experimental data. These data are shown in Table 4. 
Table 4. OSPREY predicted capacities compared to experimentally determined capacities.

\begin{tabular}{llrr}
\multicolumn{4}{c}{ Sorbent Capacity Comparison (mmol/kg) } \\
& & HZ PAN & AgZ PAN \\
\hline \multirow{2}{*}{$150 \mathrm{ppm} \mathrm{Kr}$} & OSPREY & 6.92 & 6.86 \\
& Experimental & 5.95 & 5.70 \\
\multirow{2}{*}{$1000 \mathrm{ppm}$ Xe } & OSPREY & 557.6 & 561.7 \\
& Experimental & 506.9 & 506.2
\end{tabular}

As seen in Table 4, there is a $16 \%$ and $20 \%$ difference in $\mathrm{Kr}$ adsorption on HZ PAN and AgZ PAN, respectively, between the experimental and predicted values. With respect to Xe adsorption, there is a $10 \%$ difference between the experimental and predicted capacities for both sorbents. The differences between the model and experimental data are attributed partially to the estimation of the parameters. The axial dispersion coefficient, which is proportional to the sorbent bed depth, has a large effect on when breakthrough occurs, therefore affecting the capacity. In addition, the equilibrium parameters have a large impact on the speed at which $100 \%$ breakthrough occurs, which also affects the capacity.

\section{CONCLUSIONS}

Independent isotherms were generated from capacity measurements for both HZ-PAN and AgZ-PAN sorbents. Defined $\mathrm{K}_{\mathrm{eq}}$ and $\mathrm{Q}_{\max }$ equilibrium constants for $\mathrm{Kr}$ and Xe were incorporated along with operational test conditions into the OSPREY model to predict breakthrough curves that were used to obtain capacity values which were then compared to capacities obtained during actual testing to validate model predictions. The model predictions and experimental data compared reasonably well and the differences can partly be attributed to estimation of some model parameters and the uncertainty in the experimental measurements.

\section{REFERENCES}

1. MITCHELL GREENHALGH, TROY GARN, KRISTI CHRISTENSEN, VERONICA RUTLEDGE, JACK LAW, "Summary of FY-11 Krypton Capture Activities at the Idaho National Laboratory," FCRD-SWF-2011-000312, August 2011. 